\title{
Introducing Sustainability Concepts Into University Curricula Through Systems Thinking
}

\author{
M. Kudret Yurtsevena, Walter W. Buchananb, Michael S. Pilant ${ }^{b}$
}

\begin{abstract}
The aim of this paper is to explore the major issues involved in introducing sustainability concepts into university curricula in an interdisciplinary manner, through Systems Thinking. It is generally accepted that a holistic approach is essential in sustainability studies, but teaching such a new and complex topic to a diverse student population is by no means easy. In this study, sustainability is viewed in the context of Systems Thinking, particularly in Complexity Management domain. A general framework is proposed with the intension of guiding potential instructors who are planning to teach sustainability through Systems Thinking. The framework includes only the suggested systems-oriented material and a review of some system methodologies; it does not cover sustainability issues. Methodologies known as System Dynamics and Soft Cybernetics are explored and emphasized particularly in the paper due to their importance. The framework is kept general enough so that it appeals to students and instructors with a variety of background.
\end{abstract}

\section{Keywords}

Sustainability, Systems Thinking, Complexity Management, System Dynamics, Soft System Cybernetics

Sustainable development (SD) and its education at universities have been gaining increasing attention in the last years throughout the world. Organizations of all kinds have started attaching more importance on sustainable operations nowadays. Consequently, universities are expected to prepare students who have the ability to integrate social, political, environmental, and economic considerations so that they can make sound decisions.

It should be noted that the significance of sustainability is not limited to teaching; there are some studies that go beyond teaching the subject matter and attempt to integrate SD into the functions of faculty and staff. For instance, Sammalisto, Sundstrom, and Holm (2015) examined the integration issues and proposed that SD orientation should be integrated into all university activities and an innovative educational systems thinking paradigm should be established. They also state that few studies exist that contribute to long-term sustainability implementation and training. In order to explain their point of view, the authors construct a model to illustrate development of sustainability competence and its institutionalization. The results show a large variation in perceptions of sustainability, revealing the difficulties involved in the integration of the whole process. Stanisskis and

\footnotetext{
aIzmir University, Izmir, Turkey

bTexas A\&M University, Texas, USA

Correspondent Author:

M. Kudret Yurtseven, Izmir University, Gursel Aksel Blvd. 14, Uckuyular, Izmir 35350, Turkey
} 
Katililute (2016), on the other hand, stated that most of universities have remained quite traditional as far as sustainable development is concerned; with some exceptions, they seem to be lagging behind governments and corporations.

In this general context, Marshall et al. (2010) expressed the following thoughts on the subject:

...much of our business curricula are rooted in the Industrial Age paradigm of the 20th century. This paradigm accepted as given that one need not worry about limited natural resources or irreversibility of environmental decline; it employs economically derived discount rates that are unable to capture the regenerative time scales of natural, human, and social capital; and it overestimates the capacity for anthropocentric-focused innovation to resolve pressing environmental and social issues.

They conclude their work as follows: "A paradigm shift is underway-one that necessitates the transformation of the conduct of commercial enterprise and the content of business curricula. The new paradigm incorporates a sustainability mandate, refuting clearly the old thinking of limitless resources, unbounded growth, and technologically derived solutions". Along the same lines, Adler and Harzing (2009) called for "an immediate examination of existing ranking systems" in the academic world, and to "innovate and design more reliable and valid ways to assess scholarly contributions". They argue that, historically, "the purpose of university-based scholarship was to ask important questions in rigorous ways so that the results could reliably guide society and future research" and that the present tenure system does not meet these requirements.

There are various studies on the application of sustainability in the real world. Although quite a number of the studies approach sustainability with a fairly wide vision, few are concerned with adopting a formal systems methodology. Here, mostly systems-oriented studies are reviewed.

Espinosa and Walker (2013) investigated the role of some system methodologies in sustainability management and discussed an application in an ecovillage project. They combine soft OR (Operations Research) tools SSM (Soft Systems Methodology) and VSM (Viable System Model) to develop an organizational identity and identify the core problematic issues involved; this is how they handle different perceptions and multiple worldviews in the project. Despite the limitations of the soft OR approaches, they state that their approach enhanced people's learning about a good organization and helped them to decide collectively on effective actions, leading to some improvements in the ecovillage organization and a positive effect on performance.

Horton, Koh, and Guang (2016) developed "an integrated theoretical framework to enhance resource efficiency, sustainability and human health in agri-food systems". They state that research on fully integrated decision making systems for handling diverse agri-food processes is insufficient. They propose a framework which involves "an integrated assessment of all the processes involved from the ecology of the land through to nutrition and health". The theoretical framework is consisted of an iterative methodology of four overlapping steps (Map, Analyse, Visualize, and Share), which provides "a transparent advanced methodology and collaborative decision support to all stakeholders across the agri-food ecosystems". Pagani and Otto (2013) described the procedure of group model building, while Carlman, Grönlund, and Longueville (2015) investigated collaboration between a technical-scientific group and social scientists in ecological system sustainability studies. Ceulemans, Molderez, and Van Liedekerke (2015) concentrated and examined the impact of human activities on the natural, social, and economical environment in their study. They suggest that such concerns lead organizations to become more accountable and transparent in sustainable operations.

All these studies make valuable contributions to literature on sustainability, but their theoretical basis does not appear to be strong enough. The authors of 
this paper believe that it is important to equip students with appropriate qualifications so that they learn how to think in a critical manner and adopt a holistic outlook. However, this is usually insufficient; handling complexity requires some competence in Systems Thinking and its methodologies. This is the reason why the objective of this paper is set to point out the importance of using a systems methodology in sustainability studies. The material in this paper is presented in the following order: The relationship between Complexity Management and Systems Thinking is discussed in the next section. This is followed by a brief review of some system methodologies that are relevant to sustainability and a description of the proposed framework. Conclusions provide a critical look at the theme of the paper and summarize the findings of the study.

\section{SYSTEMS THINKING AND COMPLEXITY MANAGEMENT}

Complexity Management of systems, particularly large-scale systems is one of the challenging topics in systems movement. In fact, some system methodologies have been specifically developed for dealing with complex situations and large-scale systems. According to Gorzen-Mitka and Okreglicka (2014), the origins of "modern complexity" can be traced to the foundations of General Systems Theory (GST). GST was developed as the "theory of all theories" or a "metatheory", pioneered by Bertalanfy (Skyttner 2001; 2005). It stands above all other theories, covering systems of all sizes from a cell to the universe. It is a multi-disciplinary theory, complementing the traditional scientific paradigm; it cannot be replaced. The well-known trends in GST are as follows: General Systems Thinking; Systems Approach; System Analysis; Operations Research, Systems Engineering (including Cognitive Systems Engineering); System Dynamics; System Design; Teleology; Science of Complexity; Cybernetics; and
Bionics (Skyttner 2001; 2005). All these trends view complexity from different perspectives.

It is well known that "hard" methodologies, which are mainly based on mathematical tools, received enthusiastic welcome in the management academia and business circles from 1960s to 1980s. However, these methodologies were found to be inadequate, particularly as complexity in systems and technology increased. This challenge pushed many researchers towards developing "soft" system methodologies, starting in early 1980s (Checkland and Scholes 1990; Checkland 1993). The belief in hard approaches is that any problem can be solved by setting objectives and then finding from a range of alternatives the one solution that will be optimal in satisfying these objectives via the use of hard data and hard tools. This means-end, objective-seeking approach has been found inappropriate by some systems thinkers since ends and means can be problematic themselves. For instance, conflict in strategies, decisions, and the means of achieving them leads to a new set of issues to be managed.

On the other hand, Soft Systems Thinking acknowledges that there can be different perceptions of reality, leading to different viewpoints, and eventually to different solutions. SSM, which is a well-known methodology, was developed by a team headed by Checkland at University of Lancaster in the UK (Checkland and Scholes 1990; Checkland 1993). It is viewed as a successful methodology by many researchers, including Daellenbach and McNickle (2012) and Maani and Cavana (2007). It embraces a paradigm of learning rather than viewing the world as systems whose performance can be optimized by following systematic procedures. Senge's Systems Thinking, Soft OR, Soft System Dynamics, Cognitive Mapping, SODA (Strategic Options Development and Analysis), and Soft Cybernetics are the other well-known methodologies in soft systems thinking.

It should be noted that some hard methodologies, such as System Dynamics, include soft tools for 
modeling and analysis nowadays - such as modeling employee motivation or burnout. Furthermore, a multi-methodological approach to complex systems is considered to be more effective than the use of a single methodology (Jackson 2000; 2003). The readers will find a number of applications of the multi-methodological approach, including some in sustainability—e.g. application reported by Espinoza and Walker (2013).

Spencer (2014) viewed industrial complexity as a concept or emergent property in the business world and suggested that managers can manage complexity by finding leverages in known cause-effect relationships, or by building interfaces and deconstructing complexity. According to Gorzen-Mitka and Okreglicka (2014), strategic decision-making in complex environments requires meta-cognitive skills, involving skills for innovative and adaptable decision models beyond linear thinking. Swami (2013), on the other hand, viewed decision making as cognitive processes by including theories and concepts from psychology, behavioral economics, operations research, and managerial practice. A Systems Thinking-based framework where knowledge assets are translated into organizational values in decision making is presented by Schiuma, Carlucci, and Sole (2012). A similar framework developed by Wiek and Walter (2009), is called the Transdisciplinary Integrated Planning and Synthesis (TIPS). The framework is mainly based on soft OR methods and makes use of a multi-methodological approach involving cognitive skills and habits of the stakeholders and experts, and their mutual and joint transdisciplinary learning processes. This approach was applied in a large-scale regional planning process in Switzerland.

In an interesting study, Arévalo and Espinosa (2015) approached the complexity management from a systems theoretical perspective. This work is significant in the sense that it provides a theoretical comparison of some system methodologies that are relevant to complexity management, hence to sustainability. It includes a useful discussion on the differences and similarities among complex systems theories, complex adaptive systems (CAS), and organizational cybernetics (as far as their approach to self-organization is concerned). They conclude that all these three theories aim to study nonlinear complex systems, but differ in the nature of the complex problems studied.

It appears that System Dynamics is becoming a popular approach in sustainability studies. Faham et al. (2016) explored the mechanisms needed for educating students on sustainable development and formation of student sustainability competencies. A model based on System Dynamics Methodology is used to predict the behavior of the major factors in sustainability for the next 20 years. The competencies included in the study are: (1) understanding of the sustainability; (2) skills: critical thinking in the sustainability, creative thinking in the sustainability, systemic thinking, empathy, and interdisciplinary collaboration; and (3) attitudes: commitment to the sustainability, respect for the past, present, and future generations. The external resistances are identified as the deficit of sustainability culture in the community and the budget shortage of organizations, and they are included in the model. They claim that the results show resistances and obstacles to sustainable education at the University College where the study is conducted. The researchers note that the political factors are excluded in the model due to their complexity.

Another interesting study was reported by Nabavi, Daniell, and Najafi (2016). They suggest that "System Dynamics can be a powerful tool for understanding dynamics, especially feedback behaviors, in many social-ecological systems where sustainable pathways are sought". They also add that, along with quantitative simulations and optimization packages, System Dynamics can be applied effectively and successfully, but it can also be used poorly and potentially unethically by others. In order to illustrate 
how boundary judgements affect sustainability modelling, they give three examples and discuss the potential risks and challenges involved. In addition, they warn the researchers that many sustainability studies based on System Dynamics "fall short of best practice and reflexive use of modelling methodologies".

\section{REVIEW OF SOME SYSTEM METHODOLOGIES}

Within the context of GST, the concept of complexity is formally addressed by Weiner in his work on Cybernetics (Skyttner 2001; 2005). Based on Wiener's work, Organizational Cybernetics was developed; similar to the traditional Cybernetics, the underlying principles of structure are used to explain behavior in systems. This approach is known as "structuralist" where the relationships between feedback processes operating at the deep structural level are examined, which are then used to determine the system behavior at the surface level. If we look at Beer's VSM, we see that the operation of a complex organization is created by a model based on a living organism; similar to a living organism, VSM has the ability to reconfigure itself if its environment changes.

Complexity issue was also studied by other important names in systems movement, such as Churchman, Ackoff, Weinberg, Forrester, and Gigch (Skyttner 2001; 2005). Over the last decades, Science of Complexity emerged as a new paradigm in GST. It is a multidisciplinary area, including biological organization, computer mathematics, physics, parallel network computing, non-linear system dynamics, chaos theory, neural networks, and connectionism. The primary aim of this paradigm is to try to describe the laws of complexity and understand how they generate much of the natural world and its emergent properties. Particularly, it is important to understand the conditions under which evolutionary, self-organizing, and self-complicating behavior emerges in systems. Researchers at the Santa $\mathrm{Fe}$ Institute attempted to unify some of the core system concepts into a model known as CAS, which still is an evolving construct (Snyder 2013). A good application of this approach can be seen in supply chain systems management. When managing a supply chain via CAS, analyst has the chance to model the emergent properties of the chain which are considered to be important for proper management and control. The claim is that the emergent properties cannot be modeled exclusively by other approaches, inevitably leading to weaker management structures (Christopher 2012).

Self-organizing and autonomous systems are also important in complexity management. These systems are studied extensively in Cybernetics. Accordingly, everything in the living world goes from less ordered to more ordered states, which is an irreversible process. The process of increasing differentiation, structural organization, complexity, and integration never seems to stop. Evolution creates individuals who are relatively more independent of the environment with greater autonomy. The resulting rise at the level of consciousness generates more complex collective superstructures or ecosystems. Similar to species, industries and corporations respond to changing technological development and try to survive through self-organization. These theoretical findings are then used to design better social organizations; instead of looking for main causes to build centralized control, now we have the choice of designing systems that govern themselves.

Evolution is seen as a progressive continuous change in Organizational Cybernetics and CAS, while it is interpreted as sudden changes in Complexity Sciences. In Organizational Cybernetics, self-organization takes place when there is redundancy of potential command in distributed control within the system. Complexity Sciences, on the other hand, explain the emergence of self-organization as a co-evolutionary process characterized by the absence 
of a central controller. For CAS, theory of self-organization arises from the adaptive capacity of the system to changing environmental conditions (Arévalo and Espinosa 2015). The readers should note that GST provides a strong theoretical framework for complexity management and sustainability studies.

\section{THE FRAMEWORK}

This framework is developed to guide the potential instructors so that they can arrange the Systems Thinking background material for teaching sustainability. The material is divided into two parts. Part I contains the essential topics, whereas Part II is devoted to the review of the suggested methodologies for sustainability studies.

\section{Part I: Introduction to Systems Thinking and System Methodologies}

Topics suggested are:

(1) Historical Development of Systems Thinking;

(2) Basics of General Systems Theory and Cybernetics;

(3) A Comparative View of Hard and Soft System Paradigms;

(4) Problem Context and Methodology Selection;

(5) Multi-methodological Approach and Critical Systems Thinking;

(6) Selected Case Studies.

Part II: Fundamentals of System Dynamics, Complexity Science-Organizational Cybernetics

Topics suggested are:

(1) Cybernetics and Organizational Cybernetics;

(2) Science of Complexity;

(3) Viable Systems Model;

(4) System Dynamics Methodology;

(5) Soft Systems Methodology;

(6) Case Studies.

The first part starts with a historical perspective of holistic thinking and it is a highly motivating topic. Yurtseven's (2015; 2016a; 2016b) experience shows that students perceive the subject as very exciting and participate in the discussion enthusiastically. There are very good sources available to organize this section of the course. Skyttner (2001; 2005) was strongly recommended because of his good "story telling" style. He examines the fundamentals of Systems Thinking, first in the scholastic times, and then during Renaissance and in the eras of the Classical Science, Relativity, Quantum Theory and Systems Age. He also presents pioneering thoughts and theories and discusses basic concepts of GST, together with its laws and principles, and introduces Cybernetics and Information Theory. Applications of systems theory within systems science, such as artificial intelligence, management information systems, and informatics, are also presented. The readers will find a chapter on self-organization in the 2005 edition of the book. The book is a good source for a well-rounded education.

The lectures in Part I need to be supported by selected sections from Jackson (2003) and Daellenbach and McNickle (2012). Jackson (2003) provided a historical view of systems movement and classified all the major system methodologies, both hard and soft, from a social scientist point of view. He also discusses the weaknesses and strengths of the methodologies and provides some insight into the art of choosing the appropriate methodology or methodologies for a given problematic situation. This is a theoretically strong book, but readable at the same time. Since the latest developments in systems management are compared in a critical manner, the book stands as an important source for systems management and soft systems thinking.

Daellenbach and McNickle (2012), on the other hand, approached complexity and decision making from an OR/system simulation perspective. Students of industrial engineering and business administration find this book particularly appealing. It introduces Systems Thinking, basic system concepts, problem structuring 
techniques, system modeling via graphical approach and analytical techniques, hard OR methodology, soft system methodologies, simulation and system dynamics, and decision making and risk analysis. In a way, the book extends the applications of OR methodology and simulation to complex situations through soft systems thinking. Modeling and analysis is presented via applicable tools, taking students through good examples, case studies, and exercises.

The instructors have many choices in Part II, some of which are given in the above outline. Checkland's SSM and Beer's VSM appear to be considerably successful in complexity management (Jackson 2003). However, it is relatively harder to learn and apply these methodologies, particularly VSM. System Dynamics Methodology is highly popular in many areas of application, including sustainability. This is probably due to the relative easiness in learning the methodology, and the availability of very powerful computer aided intelligent tools such as Stella. However, one should always remember the limitations of System Dynamics as mentioned by many researchers, including Jackson (2000; 2003) and Nabavi et al. (2016). Furthermore, it should not be forgotten that there is a great deal of research, both in Systems Thinking and sustainability studies. New research findings may provide better clues for handling complexity and sustainability.

\section{CONCLUSIONS}

The aim of this study was to explore the ways of teaching sustainability through Systems Thinking at the university level. The literature survey suggests that sustainability studies have a better chance of being successful if this complex phenomenon is viewed from a Systems Thinking perspective. The general framework developed here provides the basic Systems Thinking topics to be covered prior to teaching sustainability. Although the framework has enough flexibility to allow instructors to select the topics both in variety and depth in course design, it has to be tested in various academic settings. Furthermore, it should be noted that the review of system methodologies is restricted to Complexity Science-Organizational Management and System Dynamics. Further research is needed to explore the methodologies that have been left out.

\section{References}

Adler, N. J. and A. W. Harzing. 2009. "When Knowledge Wins: Transcending the Sense and Nonsense of Academic Rankings." Academy of Management Learning \& Education 8(1):72-95.

Arévalo, L. E. B. and A. Espinosa. 2015. "Theoretical Approaches to Managing Complexity in Organizations: A Comparative Analysis." Estudios Gerenciales 31(134):20-29.

Carlman, I., E. Grönlund, and A. Longueville. 2015. "Models and Methods as Support for Sustainable Decision-Making With Focus on Legal Operationalization." Ecological Modeling 306:95-100.

Ceulemans, K., I. Molderez, and L. Van Liedekerke. 2015. "Sustainability Reporting in Higher Education: A Comprehensive Review of the Recent Literature and Paths for Further Research." Journal of Cleaner Production 106:127-143.

Checkland, P. 1993. Systems Thinking, Systems Practice. Chichester: Wiley.

Checkland, P. and J. Scholes. 1990. Soft Systems Methodology in Action. Chichester: Wiley.

Christopher, M. 2012. "Managing Supply Chain Complexity: Identifying the Requisite Skills." Supply Chain Forum: An International Journal 13(2):4-9.

Daellenbach, H. and D. C. McNickle. 2012. Management Science: Decision-Making Through Systems Thinking. Ebook, Palgrave MacMillan.

Espinosa, A. and J. Walker. 2013. "Complexity Management in Practice: A Viable System Model Intervention in an Irish Eco-community." European Journal of Operational Research 225:118-129.

Faham, E., A. Rezvanfar, S. H. M. Mohammadi, and M. R. Nohooji. 2016. "Using System Dynamics to Develop Education for Sustainable Development in Higher Education With the Emphasis on the Sustainability Competencies of Students." Technological Forecasting \& Social Change, in press.

Gorzen-Mitka, I. and M. Okreglicka. 2014. "Improving Decision Making in Complexity Environment." Procedia Economics and Finance 16:402-409. 
Horton, P., L. Koh, and V. S. Guang. 2016. "An Integrated Theoretical Framework to Enhance Resource Efficiency, Sustainability and Human Health in Agri-food Systems." Journal of Cleaner Production 120:164-169.

Jackson, M. C. 2000. Systems Approaches to Management. New York: Kluwer.

_. 2003. Systems Thinking: Creative Holism for Managers. Etext, Wiley.

Maani, K. E. and R. Y. Cavana. 2007. Systems Thinking and System Dynamics: Managing Change and Complexity. New Zealand: Pearson.

Marshall, S., V. Vaiman, N. Napier, S. Taylor, A. Haslberger, and T. Andersen. 2010. "The End of a 'Period': Sustainability and the Questioning Attitude." Academy of Management Learning \& Education 9(3):477-487.

Nabavi, E., K. A. Daniell, and H. Najafi. 2016. "Boundary Matters: The Potential of System Dynamics to Support Sustainability?” Journal of Cleaner Production 140:1-12.

Pagani, M. and P. Otto. 2013. "Integrating Strategic Thinking and Simulation in Marketing Strategy: Seeing the Whole System." Journal of Business Research 66(9):1568-1575.

Sammalisto, K., A. Sundstrom, and T. Holm. 2015. "Implementation of Sustainability in Universities as Perceived by Faculty and Staff: A Model From a Swedish University." Journal of Cleaner Production 106:45-54.

Schiuma, G., D. Carlucci, and F. Sole. 2012. "Applying a Systems Thinking Framework to Assess Knowledge Assets Dynamics for Business Performance Improvement." Expert Systems With Applications 39(9):8044-8050.

Skyttner, L. 2001. General Systems Theory: Ideas \& Applications. Singapore: World Scientific.

—. 2005. General Systems Theory: Problems, Perspectives, Practice. Singapore: World Scientific.

Snyder, S. 2013. "The Simple, the Complicated, and the Complex: Educational Reform Through the Lens of Complexity Theory." OECD Education Working Papers, no. 96, OECD Publishing.

Spencer, R. W. 2014. "Managing Complexity." Research Technology Management 57(3):53-55.

Stanisskis, J. K. and E. Katililute. 2016. "Complex Evaluation of Sustainability in Engineering Education: Case \& Analysis." Journal of Cleaner Production 120:13-20.

Swami, S. 2013. "Executive Functions and Decision Making: A Managerial Review." IIMB Management Review 25(4):203-212.

Wiek, A. and A. I. Walter. 2009. "A Transdisciplinary Approach for Formalized Integrated Planning and Decision-Making in Complex Systems." European Journal of Operational Research 197(1):360-370.

Yurtseven, M. K. and W. W. Buchanan. 2015. "Decision Making via Systems Thinking in Management: Educational Issues." EPIPHANY, Journal of Transdisciplinary Studies, Special Issue: New Trends and Challenges of Today's Europe 8(2):83-94.

- 2016a. "Decision Making and Systems Thinking: Educational Issues." AJEE (American Journal of Engineering Education) — will appear in June 2016 issue.

—. 2016b. "Complexity Decision Making and General Systems Theory: An Educational Perspective." Accepted for publication in Sociology Journal (USA).

\section{Bios}

M. Kudret Yurtseven, Ph.D., associate professor, Izmir University, Izmir, Turkey; research fields: systems thinking, systems engineering, system modeling, complexity management. Walter W. Buchanan, Ph.D., professor, Texas A\&M University, Texas, USA; research fields: computer applications, pedagogy, profesional and academic issues.

Michael S. Pilant, Ph.D., professor, Texas A\&M University, Texas, USA; research field: partial differential equations. 